\section{Tolerance of Skin Heterografts in Adult Rats}

THE survival of skin heterografts can be considered as a stage in the course of research on the achievement of acquired immunological tolerance in adult animals. In earlier reports, the achievement of agammaglobulinæmia in adult animals, treated with thymic extracts from young fœetal pigs, has been described ${ }^{4}$. It has been found that these extracts render animals permanently insensitive to foreign soluble proteins ${ }^{5}$, and even to antigammaglobulinæmia serum ${ }^{6}$. Antibodies present in the serum acted against gammaglobulinæmia in experimental animals, that is, mice. The permanent tolerance of skin homografts has also been achieved in 2 adult mice ${ }^{7}$.

It seems reasonable to suppose that thymic foetal extracts, which bring about a short period of agammaglobulinamia, cause in this period the attainment of an immunological plastic state in adult animals. The state of immunological plasticity occurs physiologically in mammals and birds in the foetal or early post-natal poriod. The host's organism does not create antibodies in its later life; it begins to create them later, and to a lower degree of intensity, against antigens administered in this period $^{1-3,8-10}$.

It is very difficult to achieve the artificial tolerance of skin heterografts. The survival of skin heterografts lasting tens of days, for example, in birds which have undergone foetal parabiosis, does not occur very often

Male rats of the Wistar strain were used in the experimonts recorded here. The experiments were carried out on 10 experimental and 5 control rats 6-12 months old. The animals received hypodermic injections (for 3 weeks, 3 times a week) of thymic extracts from young fœtal pigs. On the whole, each rat received an extract (supernatant) of 800 thymuses. These extracts were prepared in the way described in previous reports. An extract amounting to $1 \cdot 5-2 \cdot 0 \mathrm{~cm}$, containing $90-160 \mathrm{mg}$ protein, was obtained from 100 thymuses. A week had elapsed after the administration of thymic extracts before the experimental rats were bled from their tail veins. Paper electrophoresis was applied to test the protein fraction content of the blood serum. Blood serum tests were repeated at intervals of 7 days until complete agammaglobulinæmia or a definite fall in the level of gammaglobulins had been achieved. Ether anæsthesia was applied during the operations. Skin grafts were covered with silk flakes imbued with liquid 'Vaseline' and paraffin 'Cellophane', dressing gauze and plaster of Paris bandages.

The experimental animals were administered 9 hypodermic injections of the supernatant of thymic extracts from young fotal pigs ( 3 injections a week). Operations were performed following the finding of agammaglobulin$æ$ mia or a marked fall in the level of gammaglobulins. A. piece of skin was depilated, its outer layer was removed, and it was substituted with a piece of tail skin of a male rat from the $C 57$ strain. The graft was dressed in the way already described.

Two pieces of skin of full thickness, each $1 . \mathrm{cm}$ in diameter, were removed from the skin of the next two rats. Two previously depilated pieces of skin of full thickness, removed from the back of a rat of the $C 57$ strain, wero inserted into the holes in the rats' skin and dressed. Immediately after the operation, the two rats received $1 \mathrm{ml}$. injections of the supernatant of an extract from the donor's (that is, a mouse of the $C 57$ strain) thymus, spleen and liver.

Experiments were carried out on five control rats; pieces of skin from the tail of a $C 57$ strain mouse were also grafted on them. Dressings were taken off the control rats on the eighth day after the operation.

Tolerance of the skin heterografts was achieved in four cases. In the first casc, the fading of a skin graft from the tail of a $C 57$ strain mouse began on the sixteenth day after the operation; in the second case it started on the twenty-sixth day; in the third case on the twenty-ninth day; in the fourth case, a full skin-thickness graft from the back of a $C 57$ male mouse survived for 110 days. In this case, the rat was administered an extract of the donor's homogenized cells. A part of the graft was injured at the moment of taking off the dressing; it became separated, and its place was covered with the host's skin. A. slip about $3 \mathrm{~mm}$ wide was tolerated and it preserved its dark pigmentation, but was not covered with hair.

In the remaining six experimental rats no tolerance of transplanted grafts was ascertained after the removal of dressings (they were taken off on the fourteenth day after the operation).

In so far as control rats are concerned, a fading graft was found in one case only; its complete demarcation occurred very soon (in a few hours' time). In the remaining cases. grafts faded and became separated before the removal of dressings. that is, before the eighth day after the operation.

\section{J. Czaplicki}

Department of Histology and Embryology,

Silesian A.cademy of Medicine, Katowice, Poland.

${ }^{1}$ Billingham, R. E., Brent, L., and Medawar, P. B., Nature, 172, 602 (1953). ${ }^{2}$ Billingham, R. E., Brent, L., and Medawar, P. B., Phil. Trans. Roy. Soc., B, 238, $357(1956)$. ${ }^{3}$ Burnet, F. M., and Penner, F., The Production of Antibodies (Melbourne,
1949).

4 Czaplicki, J., Surgery, 50, 817 (1961).

- Czaplicki, J., Surgery, 51, 645 (1962).

'Czaplicki, J., and Ivanyi, P., Folia Riologica, 9, 452 (1963).

' Czaplicki, J., Experientia, 9, 28 (1963).

${ }^{8}$ Hasek, M., Some Problems of Induction of Transplantation Tolerance. Biological Problems of Grafting, 12 (Univ. Liège, 1959).

Oven, R. D., Science, 102, 400 (1945).

${ }^{10}$ Woodruff, M. F. A., and Simpson, L., Brit. J. Exp. Pathol., 36, 494 (1955).

\section{Effect of Aldosterone on Sodium Fluxes in Larval Ambystoma tigrinum}

THere soems to be little question that aldosterone acts in mammals to facilitate sodium reabsorption from the distal tubules of the kidney. Its role in salt balance is obvious. Recrnt observations on anuran amphibians indicate that the sodium transport system in the skin and urinary bladder may also be controlled by this hormone ${ }^{1-4}$. Since uptake of sodium across the skin and renal reabsorption both serve tho same end, the observations are easily integrated into a cohorent functional and phyletic framework. However, sodium re-absorption from the kidneys of eels adapted to fresh water was unaffected by aldosterone and uptake across tho gills was markedly depressed ${ }^{5}$. Inhibition of uptake of sodium wes also noted in salt loaded euryhalino trout injected with deoxycorticosterone ${ }^{B}$. Thus the consistency of the picture apparently fails in fishes.

In the course of a detailed analysis of salt and water balance in Ambystoma tigrinum we have carried out some experiments on the effect of aldosterone on sodium balance in larvæ. Since these animals are fully aquatic they afford a simple test of an obvious variable in the already described result, namely, the fact that an aldosterone effect has been demonstrated only in animals at least partly adapted to terrestrial conditions.

The hormone was obtained as $d l$-aldosterone-21-monoacetate or as $d$-aldosteronc-21-monocetate. In either case it was dissolved in 95 per cent cthanol. This stock solution was diluted with amphibian Ringer's solution to a final concentration of $0.2 \mathrm{mg}$ aldosterone $/ \mathrm{ml}$. The control solution was made up in Ringer's solution and contained 19 per cent ethanol.

Sodium fluxes were measured with radioactive sodium (sodium-22) and flame photometry. Either influx or efflux was measured with the isotope. In the former case tho isotope was added to the bath and the influx computed from the rate of diminution in activity in the bath. In 